\title{
Focos de apatridia en Colombia: escenarios, retos y déficit de garantías*
}

Statelessness in Colombia: scenarios, challenges and guarantee deficits

Focos de apatridia na Colômbia: cenários, desafios e déficit de garantías

Foyer d'apatridie en Colombie : lieux, défis et déficit de garanties

\author{
Jorge Enrique Carvajal Martínez \\ Doctor en sociología jurídica \\ Universidad Nacional de Colombia, Bogotá - Colombia \\ Correo electrónico: jecarvajalma@unal.edu.co

\section{Andrés Mauricio Guzmán Rincón} \\ Magister en Derecho \\ Universidad la Gran Colombia, Bogotá - Colombia \\ Correo electrónico: andres.guzman@ugc.edu.co \\ Mónica Alexandra Jiménez Amorocho \\ Magister en derecho \\ Consultora independiente \\ Correo electrónico: majajimenez@gmail.com
}




\section{Resumen}

Al analizar la situación del apátrida, se observa cómo este se enfrenta a la exclusión y a la desprotección en un contexto amplio. Esto constata que la nacionalidad sigue siendo no solo una condición imprescindible para el ejercicio de derechos políticos sino también para la titularidad de los derechos humanos, lo que acentúa la discriminación y la desfavorabilidad de quienes, por diversas razones, no cuentan con esta condición. El artículo describe e identifica algunos de los escenarios en los que se evidencia este fenómeno en Colombia, y reflexiona críticamente sobre la precariedad de las garantías con las que cuenta esta población para ejercer sus derechos, lo que lleva a reafirmar su invisibilización.

\section{Palabras clave}

Apátrida, ciudadanía global, acceso a la justicia, sistema de garantías, Colombia.

\section{Abstract}

When addressing the situation of stateless people, it is observed how they face exclusion and lack of protection. This confirms that nationality continues not only to be essential for the exercise of political rights but for the ownership of human rights, which accentuates the discrimination and unfavourability of those who for various reasons have no access to it. This paper describes and identifies some of the scenarios in which this phenomenon is evidenced in Colombia, and critically reflects on the precariousness of the guarantees that this population can count on when exercising their rights, confirming their invisibility.

\section{Key Words:}

Stateless; global citizenship; access to justice; guarantee system; Colombia.

* Artículo de investigación en el marco del proyecto Acceso a la justicia global: mecanismos, tensiones y potencialidades de los sistemas internacionales de protección de los derechos humanos" del grupo de investigación Derecho Constitucional, Reforma de la Administración de Justicia y Bloques de Constitucionalidad de la Facultad de Derecho de la Universidad La Gran Colombia. Convocatoria Julio Cesar García (vigencia 2018-2019).

Cómo citar este artículo:

Carvajal, J. E., Guzmán, A. M. \& Jiménez, M. A. (2019). Focos de apatridia en Colombia: escenarios, retos y déficit de garantías. Revista de la Facultad de Derecho y Ciencias Políticas, 49 (131), pp. 303-326. doi: http://dx.doi.org/10.18566/rfdcp.v49n131.a04

Recibido: 17 de marzo de 2019.

Aprobado: 16 de agosto de 2019. 


\section{Resumo}

Ao considerar a situação do apátrida, observa-se como ele experimenta a exclusão e desproteção. Isto confirma que a nacionalidade não apenas é uma condição necessária para o exercício dos direitos políticos, mas para a titularidade dos direitos humanos, o que produz a discriminação e uma condição desfavorável para quem não a tem por diversas causas. Esse artigo descreve e identifica alguns dos cenários onde se evidencia esse fenômeno em Colômbia, além disso, analisa criticamente a precariedade das garantias dessa população para efetivar seus direitos, ao verificar sua invisibilidade.

\section{Palavras chaves:}

Apátrida, cidadania global, acesso à justiça, sistema de garantias, Colômbia.

\section{Résumé}

En abordant la situation de l'apatride, on observe comment il affronte l'exclusion et l'absence de protection. On constate que la nationalité reste non seulement une condition nécessaire pour l'exercice des droits politiques mais aussi pour la titularité de droits de l'Homme, ce qui accentue la discrimination et la défavorisation de ceux qui, pour diverses raisons, naccèdent pas à celle-ci. Larticle décrit et identifie certains des lieux où ce phénomène est mis en évidence en Colombie et réfléchit de manière critique sur la précarité des garanties que possède cette population pour exercer ses droits compte tenu de son invisibilisation.

\section{Mots clés:}

Apatride, citoyenneté mondiale, accès à la justice, système de garanties, Colombie

\section{Introducción}

La reflexión académica reciente pone de manifiesto la necesidad de transformar el concepto de ciudadanía en torno al cual se construye el Estado Nacional, para adecuarlo a una comprensión global ${ }^{1}$, que reconozca materialmente los derechos humanos universales, integrales e interdependientes ante la evidente crisis del derecho y del principio de la soberanía nacional.

$\overline{1 \text { Anota Sancari (2016) }}$ que "en las democracias contemporáneas la noción de ciudadanía excede ampliamente su aspecto político - es decir, aquellos que tienen derecho a votar y son titulares de derechos, libertades y obligaciones comunes- y tiende a extenderse en múltiples áreas del desarrollo humano" (p. 17). 
Precisamente, al acercarse a la temática en torno a la situación del apátrida, se puede observar, con mayor claridad, la manera en que este concepto, entendido de una manera restringida, excluye y mantiene en situación de desprotección a los individuos. Se puede constatar cómo, en realidad, la nacionalidad sigue siendo no solo una condición imprescindible para el ejercicio de derechos políticos sino también para la titularidad de los derechos humanos, lo que acentúa la discriminación y la situación desfavorable de amplios grupos humanos que por diversas razones son ajenos a esta condición.

En este contexto, en el presente artículo se describen e identifican algunos de los escenarios en los que se evidencia la situación de discriminación y de desprotección del apátrida en Colombia, y la configuración de dinámicas sociales y políticas que permiten comprender las particularidades de este fenómeno. Y se reflexiona críticamente sobre la precariedad de las garantías con las que cuenta esta población para hacer exigibles sus derechos, al partir de la existencia del fenómeno de la "invisibilización”, que se acentúa con algunas tensiones que impiden su reconocimiento a través de instrumentos jurídicos (a pesar de su expresa consagración en el derecho internacional), políticas públicas, y el desarrollo consecuente de mecanismos de protección.

El planteamiento que se defiende es que en Colombia al menos pueden identificarse tres escenarios en los que no existe claridad sobre el acceso a la nacionalidad y, por lo tanto, constituyen focos de apatridia: i) la situación de algunos desplazados por la violencia en el marco del conflicto armado y, en especial, de los que se ubican en territorios transfronterizos, ii) la situación de las comunidades indígenas no contactadas o en aislamiento voluntario y iii) la situación de algunos hijos de migrantes que tienen dificultades para regularizar su nacionalización. Estos tres grupos poblacionales son altamente vulnerables desde las ópticas social, económica y política, situación que se acentúa, en primer lugar, por su invisibilidad, a pesar de la existencia de normas internacionales como la Convención sobre el Estatuto de los Apátridas, de 1954, y la convención para reducir los casos de apatridia de 1961, documentos que establecen medidas en su favor. En segundo lugar, y como consecuencia de lo anterior, la precariedad de los mecanismos de exigibilidad de sus derechos que profundizan las barreras que impiden acceder a la identificación personal y a la nacionalidad.

La comprensión de una ciudadanía global que reconozca los derechos humanos universales podría tomar forma en la medida en que los Estados asuman con mayor seriedad y compromiso la protección de los apátridas, para, 
de esta manera, contrarrestar las discriminaciones generadas históricamente por un concepto de nacionalidad excluyente. La reflexión posterior deberá aportar herramientas para el fortalecimiento de las garantías constitucionales que contribuyan a la visibilización de este fenómeno y el reconocimiento pleno de derechos.

En la primera parte se reconstruye el referente teórico desde el cual se aborda la cuestión, enfatizando en el enfoque crítico y proyectivo propuesto por Ferrajoli, para reforzar las garantías constitucionales y la racionalidad jurídica en el Estado constitucional, mientras que, en la segunda, se reconstruye la situación de los apátridas, y se explicitan los tres escenarios de análisis.

\section{Punto de partida: la racionalidad jurídica y el sistema de garantías}

La concepción del derecho como sistema artificial de garantías implica una revisión de la teoría de la validez, en la que se reelabora la relación antes disociada entre vigencia y validez y forma y sustancia de las decisiones, mientras que en el plano de la teoría política reconoce, además de la dimensión procedimental de la democracia, una sustancial; en tanto que en el plano epistemológico se compromete con una función de la teoría no solamente descriptiva, sino crítica y proyectiva (Ferrajoli, 2004).

En este sentido, el autor expresa que

El paradigma del Estado constitucional de derecho - 0 sea, el modelo garantista - no es otra cosa que esta doble sujeción del derecho al derecho, que afecta a ambas dimensiones de todo fenómeno normativo: la vigencia y la validez, la forma y la sustancia, los signos y los significados, la legitimación formal y la legitimación sustancial 0 , si se quiere, la "racionalidad formal" y la "racionalidad material” weberianas. (Ferrajoli, 2004, p. 22)

Con esta formulación, Ferrajoli diferencia la vigencia o existencia de la validez; respecto de la primera entiende que hace referencia a los actos normativos y su correspondencia a normas formales. Mientras que la segunda tiene que ver con la coherencia de estos con normas sustanciales, lo que es asimilable a la validez constitucional. En ese sentido, el método de la vigencia es la subsunción, mientras que respecto de la validez, coherencia o 
compatibilidad. Por otra parte, la democracia sustancial se fundamenta en principios universales e indisponibles que se encuentran constitucionalizados y limitan la discusión pública, y la vinculan con su tutela y satisfacción. En este contexto, las decisiones políticas y jurídicas deben corresponderse con los derechos fundamentales, no solo como criterio de legitimidad sino, ante todo, como criterio de no legitimidad, al entenderse como indecidibles y sustraídos de las mayorías que tienen la fuerza discursiva de sacarlas del ordenamiento (Ferrajoli, 2004).

Lo anterior implica enormes retos para el Estado constitucional, tales como el logro de cierto grado de certeza y plenitud en el ordenamiento ante retos como la ausencia de normas que satisfagan las obligaciones para el cumplimiento de los derechos fundamentales o la posible incertidumbre que surja de la aplicación de la Constitución, precisamente es en este momento en que se requiere de las garantías entendidas como "las técnicas previstas por el ordenamiento para reducir la distancia estructural entre normatividad y efectividad, $y$, por tanto, para posibilitar la máxima eficacia de los derechos fundamentales en coherencia con su estipulación constitucional” (Ferrajoli, 2004, p. 25). Así, se le asigna al juez constitucional la guardia de estas garantías frente a los poderes del Estado y las mayorías, al detentar una posición de imparcialidad e independencia ${ }^{2}$.

Teniendo en cuenta lo anterior, en el presente ensayo se reflexionará sobre la problemática del apátrida, al identificar las situaciones en las que se configura, y al evidenciar las limitaciones de las garantías dispuestas para su visibilización y, por otra parte, el reconocimiento de los derechos de esta población vulnerable y excluida, tomando como punto de partida el hecho de que la ciudadanía o la nacionalidad no deben ser entendidas como obstáculos al reconocimiento igual de los derechos humanos de las personas y, en ese sentido, la plenitud de estas implicará suplir algunos incumplimientos y, por otra parte, integrar armónicamente las obligaciones del Estado frente a la garantía y protección de los derechos humanos de manera integral.

2 De manera similar, Ferreyra (2015) sostiene que la suerte de la Constitución depende de ese sistema de garantías, sin embargo, considera que las decisiones más importantes en una sociedad no deberían ser monopolio exclusivo de la justicia constitucional, y en ese sentido plantea la necesidad de reflexionar sobre modelos dialógicos en los que se permita que, por ejemplo, toda declaratoria de inconstitucionalidad pueda regresar a las instancias políticas (el parlamento) para su revisión, o incluso someterse a la ciudadanía para que directamente, a través de mecanismos plebiscitarios, adopte una decisión definitiva, lo que en su concepto mantendría la paz en la comunidad y dotaría de mayor legitimidad democrática el control de constitucionalidad. 


\section{La condición del apátrida: entre desprotección y exclusión}

Según la Convención sobre el Estatuto de los Apátridas de 1954, estos individuos son aquellos a quienes ningún Estado reconoce como sus nacionales conforme a su legislación interna. La nacionalidad es un vínculo con naturaleza múltiple entre una persona y un Estado, que implica el reconocimiento de derechos civiles, políticos y sociales a quienes se encuentren en el territorio. Las personas que no cuentan con dicho reconocimiento, a menudo tienen dificultades para ejercer sus derechos, especialmente en Estados donde la identificación basada en la nacionalidad es requisito para el acceso a derechos fundamentales, lo que los ubica en un plano de mayor vulnerabilidad y necesidad de protección.

En reconocimiento de esta necesidad de protección, instrumentos como la Convención sobre el estatuto de apátridas, de 1954, y la Convención para reducir los casos de apatridia, de 1961, proporcionan un marco normativo para la determinación de dicha condición, así como la regularización de la condición jurídica, y el acceso a derechos por parte de las personas en estas circunstancias.

Se estima que existen en el mundo alrededor de diez millones de personas en condición de apátridas; sin embargo, hay un amplio margen de subregistro de esta situación ${ }^{3}$, en la medida en que la mayoría de Estados no cuentan con procedimientos especiales para determinar quién es apátrida o no, por lo que formalmente solo se registran 3,7 millones de personas apátridas, en 78 países (Alto Comisionado de Naciones Unidas para los refugiados, 2015).

\subsection{El contexto: invisibilidad y barreras jurídicas}

Colombia ha ratificado la mayoría de los tratados internacionales en materia de derechos humanos que contemplan el derecho a la nacionalidad ${ }^{4}$;

3 Lo cual puede ser constatado de la comparación de estadísticas de los reportes de Global Trends del UNHCR entre el 2013 y 2015, que mantienen cifras idénticas, pese al fenómeno migratorio en aumento en toda la región, y los constantes cierres fronterizos establecidos durante los años 2015 y 2016.

4 Entre ellos el Pacto internacional de derechos civiles y políticos, la Convención americana sobre derechos humanos, la Convención sobre los derechos de personas con discapacidad, la Convención para la protección de todas las personas contra la desaparición forzada, la Convención para la 
sin embargo, respecto de los instrumentos específicos sobre apatridia, aún persisten dificultades para su plena vigencia e incorporación. En efecto, Colombia aprobó mediante la Ley 1588 de 2012, de manera conjunta, la Convención sobre el estatuto de los apátridas, de 1954, y la Convención para reducir los casos de apatridia de 1961, las cuales fueron declaradas exequibles por la Corte Constitucional colombiana a través de la Sentencia C-622 de 2013, donde se dispuso que "es válido que el Estado colombiano se vincule al tratado, mediante el depósito del instrumento de adhesión ante la autoridad del Tratado, una vez concluyan los trámites previstos en la Constitución Política”, lo que solo se llevó a cabo hasta el 13 de noviembre de 2014 como consta en el Decreto 330 de 2016, y solo respecto de la convención de 1961. Es decir, en la actualidad Colombia no ha ratificado la convención sobre el estatuto de 1954 y, con respecto a la Convención de 1961, solo se obliga desde el 13 de noviembre de 2014 la adhesión a sus lineamientos. Además, frente a este instrumento formuló una reserva al Artículo 14 en el sentido en que "no reconoce la jurisdicción de la Corte Internacional de Justicia respecto de las controversias que surjan entre los Estados contratantes referentes a la interpretación o aplicación de la Convención” (Gobierno Nacional, 2016).

Estos aspectos limitan de manera significativa el alcance interno de las normas internacionales más importantes sobre la materia, su tardía incorporación (en el caso de la Convención del 61) explican, a su vez, el hecho de que el país no cuente con registros que revelen la magnitud de la problemática, ni existan reportes de personas apátridas, teniendo en cuenta que ambos instrumentos señalan, en principio, la necesidad de identificar la condición de la apatridia, lo que influye en el establecimiento de procedimientos especiales para su determinación, inexistentes en el ordenamiento jurídico colombiano. Esta invisibilización profundiza la vulnerabilidad e indefensión en especial de aquellos a los que se les dificulta acceder a la identificación, las víctimas del conflicto armado interno, y los migrantes irregulares en tránsito.

Precisamente, en los siguientes apartados se describen los escenarios principales en los que se identifican posibles causales de apatridia en el país y se señalarán las deficiencias en el marco de las garantías.

protección de los derechos de todos los trabajadores migrantes y los miembros de su familia, la Convención sobre los derechos del niño, y la Convención para la eliminación de toda forma de discriminación contra la mujer. 


\section{Apatridia y desplazamiento forzado en el contexto del conflicto armado colombiano}

La dinámica de conflicto armado interno en Colombia, especialmente a partir de la primera mitad de los años noventa, en la que las tierras pasaron a ser el activo productivo principal de los grupos armados ilegales (Machado, 2012), bien por el control territorial, o bien por el despojo con fines de apropiación, con la resultante generación de zonas rurales con poca o nula presencia del Estado colombiano, posicionaron a Colombia como el país con mayor número de desplazados internos en el mundo, seguido de Siria e Irak (Alto Comisionado de las Naciones Unidas para los Refugiados, 2016).

De acuerdo con el reporte de la Unidad para las Víctimas ${ }^{5}$, con corte al primero de abril de 2018, un total de 7.371.504 personas habían sido registradas como víctimas de desplazamiento forzado en el marco del conflicto armado interno, ocurrido a partir del año $1985^{6}$. Este conflicto se ha librado principalmente en las áreas rurales (Centro de Memoria Histórica, 2013) en las cuales se ha expulsado al 87 \% de la población, lo que se traduce en que nueve de cada diez personas desplazadas lo han sido desde el campo colombiano (Centro Nacional de Memoria Histórica, 2015).

El desplazamiento forzado como forma de violación sistemática de los derechos humanos no empezó a ser rastreado desde sus inicios, pues no fue sino hasta la segunda mitad de los años noventa, que la magnitud de la emergencia humanitaria activó las alarmas de la problemática ante las autoridades nacionales. Inicialmente, el fenómeno se visibilizó gracias a las organizaciones de la sociedad civil y de organismos del sistema de Naciones Unidas, así como por las decisiones proferidas por la Corte Constitucional al trazar los lineamientos de política pública, que incluso hoy en día fundamentan el sistema de atención, asistencia y reparación integral a las víctimas.

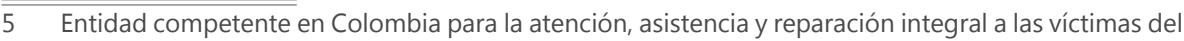
conflicto armado interno.

6 El requisito de temporalidad es señalado directamente por la Ley 1448 de 2011 o Ley de Víctimas y Restitución de Tierras.
} 
Para el año 2000, este alto tribunal, a través de la sentencia SU1150, declaró el estado de emergencia social en Colombia ${ }^{7}$ con motivo del desplazamiento forzado interno, situación que se mantendría hasta el 2004, año en el que además a través de la Sentencia T-025 de 2004 se declara el "estado de cosas inconstitucional en relación con la crisis humanitaria de las personas en situación de desplazamiento" ${ }^{\circ}$, y, en consecuencia, se le ordenó al Estado, en su conjunto, adoptar una serie de medidas para la atención de esta problemática, y se estableció una comisión de la sociedad civil para el seguimiento a las órdenes dictadas en dicha providencia, que se conoce como la Comisión de Seguimiento a la Política Pública sobre Desplazamiento Forzado, en cabeza de la cual estableció un proceso de verificación, que, a su vez, se estructuró por medio de tres encuestas complejas que se desarrollaron en 2007, 2008 y 2010.

Para la verificación de la situación, se compusieron varios indicadores de goce efectivo de derechos, relacionados con la subsistencia mínima, la identificación, la salud, la educación, la alimentación, la vivienda y la generación de ingresos. En relación con cada derecho, las tres encuestas presentaron el estado de cosas, que aunque no fueron pensadas en clave de apatridia, sí reconocieron que

la posesión de documentos de identidad acordes con la edad y el género con que se cuenta, representa para las personas desplazadas la posibilidad de acceder no solo a los diferentes beneficios y programas de atención establecidos por el Estado, sino también a las oportunidades de empleo y de generación de ingresos, diferentes a las que proveen el Gobierno Nacional 0 las entidades estatales. (Comisión de Seguimiento a la Política Pública sobre Desplazamiento Forzado, 2016).

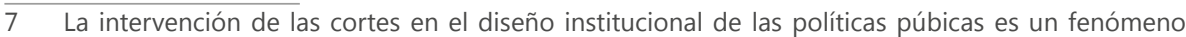
reciente en la región que se ha denominado como "judicialización" de la política; esta se entiende como "un ciclo de transferencia del proceso de toma de decisiones sobre derechos desde los órganos políticos a los judiciales (...) que conlleva mayores demandas de tutelaje hacia el poder judicial (...) esta expansión de la intervención judicial responde primariamente a una necesidad ciudadana que otras instituciones políticas no han satisfecho (...)" (Sancari, 2006, p, 130).

8 Mediante la Sentencia T-025 de 2004, la Corte conoce, a través de la acción de tutela (amparo judicial), el caso de miles de personas víctimas de la violencia que acuden a la justicia para hacer exigibles sus derechos ante las dificultades administrativas y jurídicas que presentan para acceder a la atención humanitaria de emergencia y a la oferta institucional del Estado para atender su situación y garantizarle los derechos a la verdad, a la justicia y a la reparación. La Corte, ante la constatación del masivo incumplimiento a las víctimas, quienes se veían desamparadas por la ausencia de una política pública ordenada, sistemática y articulada, decide declarar el estado de cosas inconstitucional y mediante ordenes puntuales, se propone vincular a las entidades del Estado en la adopción de una política pública con estas características, para lo cual, además, formuló lineamientos y objetivos, que son objeto de monitoreo y evaluación permanente desde entonces. 
En dicho sentido, las encuestas generadas para la verificación en materia de identidad, y principalmente las que estudian la provisión de documentos como el registro civil de nacimiento, como primera prueba de nacionalidad de los nacidos en Colombia, pueden revelar algunos resultados respecto a la población en situación de desplazamiento forzado.

Así, según la Encuesta Nacional de Víctimas, para el año 2007 el 99,1 \% de las personas desplazadas inscritas en el Registro Único de Población Desplazada, entre 0 y 6 años contaban con registro civil, situación que disminuyó en 2008 pasando a un 96,5 \%, y que aumentó nuevamente en 2010, con un 98,3 \%. Estos porcentajes significan que, para 2007 eran 463 las personas víctimas de desplazamiento forzado que no contaban con documento de identidad para acreditar su nacionalidad, para 2008 lo eran 402 personas, para disminuir significativamente en el año 2010, cuando pasaron a ser 183 personas (Comisión de Seguimiento a la Política Pública sobre Desplazamiento Forzado, 2016).

Así las cosas, una cifra considerable de menores de edad en condición de desplazamiento forzado no contaban con documentos de identificación y, por ende, al no tener prueba de su nacionalidad, se encontraban en situación de apatridia de facto, ya que la Corte Constitucional ha reconocido que las barreras administrativas para el acceso a los documentos que acreditan la nacionalidad constituyen una forma de este fenómeno, incluso cuando este tipo de riesgo sea subsanable mediante la obtención de los respectivos documentos de identidad. La forma de cuantificación a partir del Registro Único de Población Desplazada presenta como falencia el fenómeno del subregistro, pues, inclusive, muchas víctimas de desplazamiento forzado por desconocimiento, temor o barreras administrativas y económicas no pudieron declarar su condición y, por ende, no se encuentran registradas.

Ahora bien, los rangos por edad en estas encuestas son asociados a los documentos que. de acuerdo con el patrón etario, corresponden a cada grupo poblacional; sin embargo, muchas personas en los entornos rurales nunca fueron registradas $\mathrm{y}$ al documentarse en su adultez, lo que procede es la expedición del documento de identidad correspondiente en concordancia con su rango de edad. Esto significa que algunas personas desplazadas mayores de edad pudieron estar privadas de la nacionalidad, antes de la expedición de sus documentos de identidad. 
Aunque este parámetro no es analizado por las encuestas de verificación, teniendo en cuenta que no están diseñadas en clave de identificar la apatridia, vale la pena señalar que los menores entre 7 y 17 años inscritos en el registro único de población desplazada contaban con tarjeta de identidad en porcentajes del 69 \% en 2007, $62 \%$ en 2008 y 86 \% en 2010. Así también, para el caso de las mujeres mayores de 18 años, estas contaban con cédula de ciudadanía en un $97 \%$ en 2007, un $96 \%$ en 2008 y un $97 \%$ en 2010, que en el caso de los hombres mayores de 18 años no se tiene disponible para 2007, pero sí para los años 2008, con un total de 77 \% y 83 \% para 2010 (Comisión de Seguimiento a la Política Pública sobre Desplazamiento Forzado, 2016).

Estos resultados podrían indicar que la declaratoria del estado de cosas inconstitucional en materia de desplazamiento forzado, así como el seguimiento de goce efectivo de derechos, puso en cabeza del Estado la responsabilidad de garantizar el derecho efectivo a la identificación, para, de esta manera, superar la condición de apatridia de facto y acreditar su nacionalidad.

Posteriormente, la Corte Constitucional, mediante Auto 373 de 2016, al considerar que el Estado demostró avances notables en la garantía de este derecho, decidió levantar el estado de cosas inconstitucional frente a esta materia, aunque manteniéndolo para los otros derechos e indicadores de goce efectivo ${ }^{9}$. Si bien los indicadores en lo atinente a la identificación tuvieron un progreso significativo en términos de la población desplazada que pudo tener acceso a documentos de identificación, esta labor se logró precisamente en buena medida por el impulso que a este asunto le dio la Corte Constitucional a través de sus decisiones y órdenes.

\subsection{Desplazamiento forzado transfronterizo de nacionales colombianos y apatridia}

En este apartado se observarán algunos aspectos relacionados al desplazamiento forzado transfronterizo, es decir, aquel en el cual la persona desplazada ha cruzado las fronteras del territorio nacional. Con esto no quiere

9 La Corte Constitucional decidió declarar superado el estado de cosas inconstitucional en materia de identificación, en el entendido de que "el país cuenta con un registro que permite, pese a las dificultades que aún se presentan, avanzar en su identificación y en su progresiva superación, excepto para pueblos y comunidades étnicos" (Auto 373, 2016). 
decirse que el fenómeno de la apatridia en migrantes colombianos se encuentre restringido a las personas víctimas de desplazamiento forzado, sin embargo, siendo estas sujetos de especial protección y migrantes en contextos de extrema vulnerabilidad, resultan tener mayor proclividad a la informalidad en materia de identificación, y por ende, a la situación de apatridia. No obstante, la normatividad en materia de nacionalidad, y particularmente en lo que atañe a los nacimientos sucedidos en el exterior, es aplicable tanto a desplazados como a migrantes en otro tipo de contextos, por lo que esta situación puede hacerse extensiva a otro tipo de población.

Con más de siete millones de personas desplazadas forzosamente, y con un registro de víctimas que presenta la individualización por hecho victimizante, aún se dificulta la cuantificación de las víctimas que iniciaron su desplazamiento dentro del territorio colombiano, y cruzaron las fronteras en búsqueda de la preservación de su integridad física y la de sus familiares. Aunque Colombia tiene casi cinco millones de personas que han migrado al exterior, solo 400000 tienen estatus de refugiados o están en el proceso para serlo (El Tiempo, 2015).

La condición de refugiado, contrario a la de desplazado, se adquiere mediante declaratoria, es decir, la protección desencadenada a partir del estatus de refugiado solo se produce a partir de su determinación. Colombia es el país de las Américas que como nación expulsora presenta mayor número de solicitantes de refugio, con un estimado de 400000 (Centro Nacional de Memoria Histórica, 2015). Sin embargo, se estima también que más de la mitad de los desplazados que han cruzado fronteras no han solicitado refugio y, por lo tanto, hay un amplio margen de subregistro en países como Venezuela, Ecuador y Panamá (El Tiempo, 2015).

El cruce de fronteras no necesariamente significa para los desplazados colombianos la mejora de sus condiciones, pues su desplazamiento se realiza de manera prácticamente idéntica en cuanto a goce efectivo de derechos se refiere, si se compara con los desplazados internos. Es por eso que, por lo general, los desplazados se asientan en barrios de periferia o invasión, en los que la marginalidad es la constante, y no se cuenta con servicios para la atención de derechos en salud, educación o saneamiento básico. Tal es el caso de las personas desplazadas en Ecuador, ubicadas en las provincias de Esmeraldas, Carchí e Imbabura y Sucumbíos; en Panamá, en las provincias de Darién y Guna Yala; y en Venezuela, en los Estados de Zulia, Táchira, Apure y Amazonas (Centro Nacional de Memoria Histórica, 2015). 
A esta situación se le suma el hecho de que la mayoría de desplazamientos se realizan en condiciones de urgencia y precariedad extremas, en las que las personas no tienen la posibilidad de trasladar con ellas sus posesiones, entre ellas su propia documentación, lo que les dificulta, entonces, la regularización de su situación migratoria, así como la propia determinación como refugiados. Asimismo, siendo la población rural también carente en la mayoría de los casos de educación básica o secundaria, y encontrándose apartada de entornos en los cuales se brinde acceso a la información en relación con sus derechos (pensando en clave de asistencia, atención, reparación o identificación), la situación de vulnerabilidad es sostenida en el tiempo e inclusive transmitida a los descendientes.

Para los niños y niñas ${ }^{10}$ hijos de colombianos migrantes esta situación se ve agravada si se tiene en cuenta que dentro de los criterios para la adquisición de la nacionalidad colombiana se encuentra el registro del nacimiento en oficina consular, cuando este se produzca en el exterior. Por esta razón, los hijos de colombianos nacidos en el exterior no reciben automáticamente la nacionalidad colombiana, y cuentan con serias dificultades para su adquisición posterior, en la medida que el registro en territorio colombiano requiere también de la presentación de ciertas formalidades como el certificado de nacimiento debidamente apostillado o legalizado, o la presentación de declaración juramentada de dos testigos que presenciaran el hecho del nacimiento.

La situación de apatridia, sin embargo, y dependiendo del lugar de recepción del desplazado transfronterizo, puede haber sido superada en casos como el venezolano, pues la Constitución Política de este país (Art. 32) aplica el ius soli sin condicionamientos, de manera que cualquier persona nacida en este territorio tiene derecho a la nacionalidad de dicho país, en igual circunstancia los casos panameño (Art. 8 de la Constitución Política de Panamá) y ecuatoriano (Art. 7 de la Constitución Política del Ecuador).

10 De acuerdo con el Centro Nacional de Memoria Histórica (2015) Ob. Cit. Pp. 465, "la invisibilización de las víctimas es mayor cuando se trata de niños, niñas y adolescentes, así como de indígenas. En el primer caso, con ocasión del conflicto armado y la violencia sociopolítica y económica, miles de niños, niñas y adolescentes se han visto forzados a cruzar, solos o acompañados, las fronteras nacionales en búsqueda de protección o refugio. Por otra parte, miles de niños, niñas y adolescentes son hijos o hijas de víctimas del éxodo transfronterizo, que nacieron fuera de Colombia y crecieron en hogares que, al haber huido del conflicto armado y la violencia, les transmitieron la 'sensación de peligro y amenaza que persiste en los padres'. De esta manera, los niños, niñas y adolescentes no solo son víctimas directas del éxodo transfronterizo, sino que reflejan la trascendencia generacional de los daños inherentes a esta forma de violencia". 
La superación de la condición de apatridia en estos casos es, sin embargo, una mera conjetura, pues la realidad, aún sin registros especiales, puede mostrar otro panorama. A manera de ejemplo se destaca la situación de colombianos deportados desde Venezuela a Colombia cuando en agosto de 2015 el presidente de la república, Nicolás Maduro, decretó el estado de excepción en la ciudad de San Antonio en el estado de Táchira (fronterizo con Colombia), hecho que significó deportar más de mil colombianos sin que fueran verificadas ni su nacionalidad ni su situación migratoria (El Heraldo, 2015), tampoco si eran población desplazada o migrantes económicos (Rincón \& Suarez, 2015).

Ante esta situación, la atención humanitaria se enfocó en la población recibida en las ciudades y poblaciones limítrofes con Venezuela, en donde se evidenció la falta de registro particularmente de menores hijos de padres colombianos nacidos en el país vecino. En respuesta a ello, la Registraduría Nacional del Estado Civil ha venido adoptando medidas encaminadas para garantizar su inscripción y, en consecuencia, su derecho a la nacionalidad, con algunos criterios excepcionales, entre ellos la recepción de certificados de nacimiento sin apostilla y mediante declaración de dos testigos, teniendo en cuenta que la mayoría de deportados eran población en situación de pobreza extrema, desplazados forzosamente, o personas que no contaban con algún tipo de identificación (Registraduría Nacional del Estado Civil, 2017).

Pese a la vaguedad y falta de cifras concretas sobre el registro de esta población, es claro que los desplazados forzosamente que han cruzado la frontera no necesariamente han transitado hacia la formalización de su situación, incluso la consagración de la nacionalidad bajo criterios del ius soli en los países vecinos tampoco es una garantía certera, las deportaciones masivas que se mencionaron así lo demuestran. Sin embargo, la flexibilización de los criterios para acceder al registro como presupuesto de la nacionalidad en situaciones excepcionales y bajo principios estrictamente humanitarios se considera un avance importante.

\section{Pueblos indígenas no contactados o en aislamiento voluntario}

El Estado colombiano se reconoce desde su Constitución Política como multicultural y pluriétnico, y establece como obligación la protección de 
la identidad cultural, así como del territorio como elemento básico para la supervivencia de los pueblos indígenas y de las comunidades negras.

En Colombia existen alrededor de 87 etnias indígenas identificadas, correspondientes al 3,3 \% de la población total del país (Departamento Administrativo Nacional de Estadística - DANE , 2008). Aunque la mayoría de los grupos indígenas han sido contactados e identificados, la mayoría se encuentra en condiciones precarias que amenazan su identidad cultural, o los derechos al territorio.

Es importante mencionar que, en Colombia, las subregiones amazónica, pacífica y de la Orinoquía se componen de inmensas extensiones selváticas en las cuales históricamente no ha habido una presencia institucional del Estado significativa, lo que ha facilitado la existencia de comunidades indígenas no contactadas, con contactos precarios o indirectos, o en aislamiento voluntario, fenómeno que se da principalmente en partes del territorio inaccesibles y en vastos territorios inexplorados. Por ejemplo, los Nükak, son conocidos como el último pueblo indígena de tradición nómada sin contacto oficial, ni siquiera con otros grupos indígenas con presencia en la misma subregión hasta 1988 y que se ubican entre los departamentos de Guaviare y Vaupés (subregión amazónica) (Instituto de Promoción de Estudios Sociales, 2012).

El proceso de contacto estuvo minado de factores que aceleraron la disminución de esta etnia, y la posicionan como una de las que se encuentran en peligro de desaparición, ya que se pasó de 2000 a 600 miembros en el año 2000, afectados por circunstancias como: i) el contacto con enfermedades propias de los blancos o kawene, como se denominan en lengua nükak, ii) la situación de conflicto armado que generó que entre 2002 y 2008 fueran desplazadas más de 300 personas, iii) El proceso de aculturación y iv) el avance de la colonización de territorio indígena (Instituto de Promoción de Estudios Sociales, 2012).

Se estima que, como lo eran los nükak en su momento, en la actualidad existen aproximadamente 200 pueblos indígenas en aislamiento o sin contacto, ubicados en Suramérica , en los países de Colombia, Venezuela, Ecuador, Brasil, Perú, Bolivia y Paraguay. Inclusive, para 2012 se reportó la existencia de otro pueblo no contactado en la Amazonía colombiana (Ruiz, 2012).

No hay una definición consolidada sobre esta condición, sin embargo, se acepta que son pueblos indígenas que "no mantienen o nunca han 
mantenido contactos regulares con la población fuera de su propio grupo, y que suelen rehuir el contacto con tales personas ajenas a su grupo" (Instituto de Promoción de Estudios Sociales, 2012, pág. 16), es decir, estos grupos básicamente permanecen en las mismas condiciones que antes del proceso de colonización europea en las Américas. Por otro lado, el aislamiento voluntario corresponde a grupos que, aunque han tenido contacto intermitente con personas pertenecientes al segmento mayoritario de la población, no establecen relaciones con dichas sociedades y retornan al aislamiento.

La naturaleza aislada de estos grupos humanos dificulta la cuantificación de la población, así como la determinación exacta del territorio que ocupan, sin embargo, esta situación no puede negar su existencia, en la medida que hay múltiples reportes de avistamientos, que han llevado a países como Perú a emitir normatividad relacionada con su protección ${ }^{11}$, o Ecuador y Brasil a determinar áreas específicas para la conservación de este tipo de población. En Colombia, inclusive, el Decreto Ley 4633 de 2011, enfocado a la atención, asistencia y reparación integral de víctimas pertenecientes a pueblos indígenas, ha reconocido la especial protección de estas personas, y la garantía de que "en ningún caso podrán ser intervenidos o despojados de sus territorios, ni serán objeto de políticas, programas o acciones, privadas o públicas, que promuevan el contacto o realicen intervenciones en sus territorios para cualquier fin” tal y como se formula en el artículo 17.

La Constitución Política de 1991, que incorporó algunos derechos específicos de los pueblos indígenas y comunidades tribales en atención del Convenio No. 169 de 1989 de la Organización Internacional del Trabajo (en adelante OIT), establece un marco específico de obligaciones en cabeza del Estado colombiano, para garantizar la pervivencia y protección cultural de la identidad de estos pueblos. Adicionalmente, el Artículo 40 superior establece que la cultura es un fundamento de la nacionalidad, lo cual, al menos en un ejercicio hermenéutico, podría facilitar la garantía de derechos a personas que, como los pueblos indígenas no contactados o en aislamiento, no pueden probar su identidad, pero sí habitan y pertenecen a la nación.

La existencia de este tipo de población introduce un aspecto pocas veces tratado en el marco de las situaciones de apatridia, en el entendido de que, al

11 El Perú cuenta desde 2006 con una ley para la protección de los pueblos indígenas u originarios en situación de aislamiento y en situación de contacto inicial. 
estar relacionada intrínsecamente con el concepto de nacionalidad, presupone la existencia de naciones, las cuales, a su vez, deben estar reconocidas internacionalmente bajo la figura de Estados. En ese entendido, los pueblos indígenas no contactados o en aislamiento voluntario, lógicamente no tendrían relación con el Estado en el cual se encuentran ubicados sus territorios, lo que significa que no cabría posibilidad de identificación y, como consecuencia, adopción de nacionalidad. Por otro lado, tampoco serían reconocidos nacional o internacionalmente como Estados o naciones indígenas en sí mismas, lo cual, en términos prácticos limitaría la protección de sus derechos.

Bajo estas premisas, los derechos de los pueblos indígenas no contactados o en aislamiento voluntario, aunque humanos y fundamentales, no serían los mismos que los que se limitan usualmente a las personas individuales en situación de apatridia, en el entendido de que estos colectivos precisamente por su aislamiento y prácticas de vida, no requerirían de servicios y derechos tales como la educación, o el trabajo, o todos aquellos que dependan de la prestación de servicios por parte del Estado, pero sí de otros de naturaleza colectiva como el territorio, la familia, el goce de un ambiente sano, la protección de la cultura y la garantía de reproducción de la misma.

En términos materiales, las personas pertenecientes a pueblos indígenas no contactados o en aislamiento voluntario no serían nacionales colombianos, teniendo en cuenta que, al no estar en contacto con el Estado, no tienen forma de acreditar la nacionalidad colombiana $y$, por ende, existe una barrera administrativa creadora de un riesgo de apatridia. Por otro lado, su misma ubicación y aislamiento indican que no son nacionales de otros países, pero que la intervención en estas comunidades, bien por parte del Estado colombiano, o bien por parte de otro , significaría inevitablemente poner en peligro la identidad y conservación cultural y física de estos pueblos, como ya la experiencia lo ha comprobado. Pese a lo anterior, al encontrarse en jurisdicción de territorio colombiano, e inclusive habitar en este con anterioridad a la consolidación del Estado mismo, existen obligaciones de protección a su favor.

Dada la inusual forma de apatridia que viven los pueblos indígenas no contactados o en aislamiento voluntario, los instrumentos en la materia no cuentan con disposiciones específicamente dirigidas a su protección. Las acciones que puedan tomarse en la materia, aunque en línea con instrumentos como la Convención No. 169 de la OIT o la Declaración de Derechos de los Pueblos Indígenas de las Naciones Unidas, podrían considerarse restrictivas 
para los Estados, y supeditadas al conocimiento de la existencia de este tipo de población, aunque garantizando la no intervención.

El principio de no intervención en estos casos resulta fundamental, teniendo en cuenta que, desde cualquier perspectiva, la intervención en territorios habitados por este tipo de población significa un detrimento en su integridad, y un menoscabo de todos los derechos fundamentales de los pueblos indígenas sin contacto. Sin embargo, la consolidación de protección para esta población sin realizar intervención alguna, representa retos y dificultades nunca antes tratados, y en cierta medida, etéreos, pues significan, en términos prácticos para los Estados, limitaciones tales como la imposibilidad de expansión (en materia de infraestructura, bienes y servicios) en lugares puntuales sin la posibilidad de que estos sean delimitados, así como la restricción de explotación de recursos, y la formulación de planes específicos para la atención y salvaguarda de esta población en los eventos en los que voluntariamente decidan contactarse.

\section{Migración de apátridas o hijos de migrantes nacidos en territorio colombiano}

Teniendo en cuenta que Colombia no cuenta con un registro de personas apátridas, y que la nacionalidad no es un derecho que surja automáticamente sino que debe ser solicitado, inclusive para los hijos de nacionales colombianos, la situación para hijos de extranjeros con imposibilidad de transmitir su nacionalidad porque no cuenten con ella, o las leyes de su país de origen no lo facultan para transmitirla, o de adquirir la nacionalidad colombiana sin residir formalmente en el país, se convierte en un foco de apatridia que aún no ha sido dimensionado efectivamente.

Sea lo primero recordar que la nacionalidad por nacimiento, de acuerdo con la Constitución Política colombiana, se puede adquirir cuando se nace en territorio colombiano, siendo hijo de padres extranjeros domiciliados en el país. Esta limitación al domicilio, inicialmente hacía alusión no solo a la voluntad de permanencia, sino a la acreditación de esta situación a través de lo que se había denominado como "visa de residente", o de otros tipos de 
visados contemplados en la reglamentación interna colombiana ${ }^{12}$, a través de los cuales se exigen formalidades y se establecen requisitos.

La posición geográfica de Colombia, aunada a la facilidad de conectar migrantes provenientes de diversos lugares del mundo, lo convierten en un país receptor transitorio.

Los cierres fronterizos de la República de Panamá el 9 de mayo de 2016 para prevenir el tránsito irregular hacia Estados Unidos, medida que también adoptaron países como Costa Rica y Nicaragua, posteriormente, acentúan este hecho.

La “Operación Escudo”, como fue designada en Panamá el cierre fronterizo, originó el represamiento en Turbo, Antioquia, de 1273 migrantes, principalmente cubanos, de los cuales 300 eran menores de edad, pero también otros tantos provenientes de la República Democrática del Congo, Haití, Ghana, Senegal, Nepal, Pakistán, Malí, Guinea, Gambia, Somalia, Bangladesh, Angola, Afganistán, Eritrea, Camerún, Sierra Leona y Togo (Consultoría para los Derechos Humanos y el Desplazamiento - CODHES, 2016).

Estudiar la nacionalidad de origen de los migrantes es un asunto clave para determinar nuevos focos de apatridia que incluyan el registro y filtro por criterios de género, teniendo en cuenta que, en la actualidad, 27 países en el mundo cuentan con legislación que impide que las mujeres transmitan la nacionalidad a sus hijos, o que puedan hacerlo solo bajo la aplicación de ciertos procedimientos. De manera específica, países como Nepal, Somalia, Sierra Leona y Togo, de los cuales se han reportado migrantes irregulares, cuentan con barreras de acceso a la nacionalidad por género (Institute on Statelessness and Inclusion, 2016).

Frente a este fenómeno, el país podría permitir el acceso a la nacionalidad colombiana para los menores que, de otra forma, estuvieran en riesgo de apatridia, o al menos permitir la estancia regular en el país hasta tanto sea

\footnotetext{
12 La Resolución 6045 de 2017, que derogó a la Resolución N.․ 5512 de 2015, estableció tres tipos de visados de acuerdo con los destinatarios, así: visitante, migrante y residente. En consecuencia, actualmente se mantienen requisitos formales para el establecimiento del domicilio en el país, bajo las categorías de residente o migrante, lo que quiere decir que, en todo caso, el acceso a la nacionalidad para los hijos de migrantes está supeditada a la situación migratoria de los padres, quienes deben satisfacer estos requisitos.
} 
resuelta la situación migratoria. Sin embargo, la respuesta predominante ha sido la deportación ${ }^{13}$. Según la Consultoría para los Derechos Humanos y el Desplazamiento (CODHES), los migrantes, principalmente cubanos, se dirigen hacia los Estados Unidos con el fin de ser beneficiarios de la Ley de Ajuste Cubano, según la cual si logran pisar suelo estadounidense tienen el derecho de contar con residencia permanente.

Los migrantes irregulares se ven afectados por una serie de hechos particulares, especialmente los relacionados a la prostitución forzada, tráfico de drogas, armas o dinero, participación forzada en narcotráfico, extorsión, homicidio o desaparición forzada, entre otras, lo que acentúa su vulnerabilidad y la necesidad de protección internacional.

Es importante mencionar que, de acuerdo con la Circular 168 de 2017, los hijos de extranjeros nacidos en territorio nacional pueden acceder a la nacionalidad colombiana siempre y cuando sus padres acrediten el domicilio, aunque se establece una excepción a este último requisito respecto de aquellos que no puedan transmitir la nacionalidad. No obstante, al no existir un procedimiento para la determinación de la condición de apatridia, tanto para los padres como para sus hijos nacidos en territorio colombiano, en la vida real se les priva de beneficiarse de la mencionada excepción y en consecuencia del acceso a la nacionalidad.

\section{Conclusiones}

En el transcurso del presente análisis se demostró que el Estado colombiano ha limitado deliberadamente el alcance interno de las normas internacionales más importantes sobre la materia, a través de su tardía incorporación, la formulación de reservas frente a aspectos sustantivos de estas normas e incluso la falta de voluntad política para agotar el trámite de ratificación. Aspectos que han incidido en una significativa invisibilidad de este fenómeno que agrava y acentúa la vulnerabilidad de estas personas que no cuentan con garantías concretas para su reconocimiento y acceso a derechos a través de la nacionalidad.

13 Según los datos de Migración Colombia, durante 2016 han sido deportados 540 migrantes irregulares, de los cuales el $40 \%$ tiene nacionalidad haitiana y el $25 \%$, cubana, aunque no todos ellos se deportaron a sus países de origen, sino que, en virtud de las normas migratorias, fueron devueltos al último país de procedencia, que en la mayoría de los casos es Ecuador. 
Se debe destacar cómo algunas decisiones de la Corte Constitucional han contribuido a ampliar la protección de esta población a través del acceso a la identificación personal de ciertos grupos, pero persisten dificultades no solo jurídicas sino institucionales para garantizar los derechos que se derivan de esta. Además, la persistencia del conflicto armado interno y la relación que este tiene con la poca o nula presencia institucional del Estado colombiano en ciertas regiones del país acentúan la vulnerabilidad y hace que sea inminente una reflexión más profunda en la sociedad sobre estos aspectos para contrarrestar de manera efectiva la discriminación que esta apareja si se toma en serio la Constitución.

La naturaleza de la migración de los apátridas en territorio colombiano, en especial, respecto de los migrantes irregulares en tránsito, dificulta su identificación, el dimensionamiento de la problemática, y facilita la exclusión de responsabilidad del Estado colombiano, pues generalmente estas personas no tienen acceso a un recurso judicial efectivo, y las vulneraciones que sufren no cuentan con registro alguno. Sumado a esto, los hijos de migrantes irregulares en tránsito nacidos en territorio colombiano mantienen su condición de apátridas durante el periodo de migración; además, en algunos casos tampoco cuentan con pruebas de registro de su nacimiento.

Considerar la protección de derechos de apátridas de facto en nuevos contextos, como el de los pueblos indígenas no contactados o en aislamiento voluntario, es un reto pendiente de los países latinoamericanos con pueblos originarios cuyos derechos, individuales y colectivos, se diferencian de los derechos de apátridas migrantes o inclusive apátridas in situ pertenecientes a comunidades étnicas, pero con formas organizativas o prácticas de vida que no dependen exclusivamente del aislamiento y la protección del territorio.

\section{Referencias}

Alto Comisionado de Naciones Unidas para los refugiados. (2015). Global trends. Ginebra: UNHCR.

Alto Comisionado de las Naciones Unidas para los Refugiados.(2016). Alto Comisionado de las Naciones Unidas para Tendencias Globales sobre refugiados y otras personas de interés del ACNUR. Ginebra: ACNUR.

Auto, 373 (Corte Constitucional de Colombia 2016). 
Centro Nacional de Memoria Histórica.(2015). Una Nación desplazada - Informe nacional del desplazamiento forzado en Colombia. Bogotá: Centro de Memoria Histórica.

Comisión de Seguimiento a la Política Pública sobre Desplazamiento Forzado. (2016). Análisis sobre el Estado de Cosas Inconstitucional. Bogotá: CODHES.

Consultoría para los Derechos Humanos y el Desplazamiento - CODHES. (2016). Llamado urgente a proteger los derechos humanos de los migrantes represados en Turbo, Antioquia.

Departamento Administrativo Nacional de Estadística - DANE.(2008). La experiencia de la identificación étnica en los censos de población de Colombia. Los retos para el próximo censo. Bogotá: DANE.

El Heraldo. (2015, agosto 25). El drama de los deportados colombianos por crisis en la frontera con Venezuela. Barranquilla, El Heraldo. https://www.elheraldo. co/internacional/el-drama-de-los-deportados-colombianos-por-crisis-envenezuela-213349

El Tiempo. (2015, Junio 28). Colombia Refugiada. Bogotá, El Tiempo. https://www. eltiempo.com/multimedia/especiales/refugiados-migracion-y-desplazamientode-colombianos/15503358/1/index.html

Ferrajoli, L. (2004). Derechos y garantías la ley del más débil. Madrid: Trotta.

Ferreyra, G. (2016). Manuscrito sobre una procura de paz en Colombia. Revista de la Secretaría del Tribunal Permanente de Revisión, 393-429.

Gobierno Nacional. (24 de febrero de 2016). Decreto 330 de 2016 "por medio del cual se promulga la "Convención para Reducir los Casos de Apatridia", adoptada en Nueva York el 30 de agosto de 1961.

Grupo de Memoria Histórica.(2013). ¡Basta ya! Colombia: memorias de guerra y dignidad. Bogotá: Centro de Memoria Histórica.

Institute on Statelessness and Inclusion.(2016). Protecting a Mother's Nationality Rights: Countdown from 27 to Zero. Amsterdam: ISI.

Instituto de Promoción de Estudios Sociales.(2012). Pueblos indígenas en aislamiento voluntario y contacto inicial. Los Núkak, el último pueblo de tradición nómada contactado oficialmente en Colombia. Bogotá: IPES.

Machado, A. (2012). El problema de la tierra en Colombia y desarrollo humano en el sector rural - sectores sociales populares para la paz en Colombia. In A. Machado, La cuestión agraria en Colombia: tierra, desarrollo y paz (pp. 26-31). Bogotá: Planeta Paz. 
Registraduría Nacional del Estado Civil. (2017). Registraduría Nacional prorrogó medidas excepcionales para registro civil de menores, hijos de colombianos nacidos en Venezuela. Registraduría Nacional del Estado Civil. https://www.registraduria.gov. co/Registraduria-Nacional-prorrogo.html

Rincón , C., \& Suárez, A. (2015, agosto 29). El drama de los vecinos de mi pequeña Barinas. El Tiempo. https://www.eltiempo.com/archivo/documento/CMS-16309844

Ruiz, J. (2012, agosto 28). Pueblos indígenas aislados y minería. El Espectador. https:// www.elespectador.com/opinion/pueblos-indigenas-aislados-y-mineria

Sancari, S. (2006). La jurisprudencia sobre la legislación de emergencia económica y sobre el amparo. Análisis desde una perspectiva politológica. In S. Sancari, \& J. Bercholch, La Corte Suprema en el sistema político (pp. 121-218). Buenos Aires: Ediar.

. (2016). La participación política en la Argentina. Buenos Aires: Facultad de Derecho. 